\title{
Psychological Injury and Law: Editorial Policies on Defamation and Disclosure
}

\author{
Gerald Young
}

Received: 18 January 2009 /Accepted: 22 January 2009 /Published online: 21 February 2009

(C) Springer Science + Business Media, LLC 2009

\begin{abstract}
In this editorial, to initiate the second year of the journal, the editor describes some critical journal policies. In particular, the editorial examines defamation, disclosure of conflict of interest, citing unpublished research and data, and manuscript submission review procedures.
\end{abstract}

Keywords Editorial policies · Defamation · Disclosure · Unpublished research

\section{Editorial Policy on Defamation and Libel}

The academic publishing environment has been shaken by articles and books exhibiting ethical violations, documented cases of fraud, lack of disclosure of conflicts of interest, and published defamatory remarks. In this difficult publishing environment, scholarly, scientific peer-reviewed journals such as Psychological Injury and Law (PIL) need to adopt the strictest of publishing standards and editorial policies, both in terms of what is expected in submitted manuscripts, in disclosure by their authors, and in the review process of the submissions and disclosure by reviewers. In Young (2008), to initiate the journal, I elaborated journal policies and information for authors. In the present editorial, to initiate the journal's second year, I continue this process.

The association that houses PIL, the Association for Scientific Advancement in Psychological Injury and Law

Gerald Young, Department of Psychology, York University

Many thanks to Andrew Kane and Izabela Schultz for helpful comments on the text

G. Young $(\bowtie)$

Department of Psychology, Glendon College, York University,

2275 Bayview Ave.,

Toronto, ON M4N 3M6, Canada

e-mail: gyoung@glendon.yorku.ca
(ASAPIL), has adopted rigorous policies pertaining to potential defamation and libel (Young 2009; based on Jacobs 2007; Jacobs and Ogden 1995).

Defamation and libel involve dissemination of false or misleading facts or false or misleading implied facts that might be damaging to the reputation of the aggrieved party. Defamation and libel might be committed despite belief by the individual or entity that is the truth is being communicated. The statement must be derogatory or damaging to reputation, for example, involving accusation of dishonesty or other moral deficiency. In many or most legal jurisdictions, by taking reasonable precautions to ensure accuracy in every detail, the individual will not be held liable for defamation or libel, even if a statement turns out to be false and defamatory or libelous.

\section{Disclosure of Conflict of Interest}

Bigler et al. (2009) have published an article in the present issue of PIL that suggests a policy that the journal should adopt with respect to full disclosure about the categories that they present, at least where they are applicable. The authors used a format in which they disclosed: (a) author contributions; (b) study concept and design; (c) acquisition of data; (d) analysis and interpretation of data; (e) drafting of the manuscript; (f) critical revisions of the manuscript for important intellectual content; (g) statistical analysis; (h) administrative, technical, and material support; (i) supervision; (j) financial disclosures; and (k) funding/support.

In addition to Bigler et al. (2009), Williams et al. (2009), in an article that is tentatively scheduled for publication in the next issue of this journal, have disclosed fully all relevant potential conflicts of interest in their article. Both articles referred to PIL as having good disclosure policies. Both articles stand as excellent models on how to proceed in 
achieving full disclosure for publication purposes in this journal. The two principle authors in Williams et al. even have a website dedicated to full disclosure in their research.

The American Psychological Association (downloaded January 18, 2009), which sponsors many psychological journals, has an explicit disclosure form asking for full disclosure of interests. It is the opinion of the PIL journal board that authors of submissions must examine and adhere to the provisions of the APA form, which is available at $\mathrm{http}: / /$ www.apa.org/journals/authors/disclosure_of_interests. pdf. The form indicates that psychological publications presumably are based on "objective interpretations of evidence and unbiased interpretations of fact." Any economic and commercial interests held by authors that might "color" or "distort" the required objectivity should be disclosed, even if the authors maintain that there is no conflict or bias (e.g., holding copyright of and/or receiving royalties from a psychological test). Authors should consider disclosing circumstances that could be interpreted as "bias against a product, service, facility, or person" (e.g., an author has a copyright or royalty interest in a competing psychological test or assessment protocol to the one being criticized).

Another example that I provide relates to disclosure of the specifics of grants, disbursements, gifts, noncompetitive financial sources, or other financial underwriting of manuscript submissions and the research described therein. This is especially important in the field of psychological injury and law, where the plaintiff and defense sides of the legal divide might provide monies for research projects and authors but wish that they remain anonymous. There are important examples of pharmaceutical companies paying medical doctors for their research, without the doctors disclosing the source of their funding.

It is important to note that PIL requires not only authors but also reviewers to adhere strictly to these disclosure policies. For Volume 1 of the journal, when authors submitted manuscripts without disclosure and conflict of interest statements, I assumed that none were at issue. Beginning with the second volume of the journal, all authors must adhere to the strictest of disclosure requirements and, where it is applicable, state explicitly that there are no conflicts of interest and related matters involved in their submissions. Reviewers are asked to consider the same for each article that they review. The board members of this journal are not investigators, and we will trust the truth value of the disclosures made, unless available evidence indicates that further inquiry is necessary.

\section{Citing Unpublished Research and Data}

Psychological injury and law is an area that vets at two levels the quality of research in the field. First, journals are gatekeepers of the quality of their publications, and an independent and impartial review process works toward guaranteeing that empirical research meets the highest standards of science. Books are published with less particular scrutiny, but proposals are vetted by senior workers in the field, and often, the reputation of authors for the quality of their publications in journals precedes them as book authors. The second level of screening the quality of research in the area happens in court, where judges function as gatekeepers of evidence admitted to court. They have an imperfect grasp of science compared to researchers, but they do recognize the value of peerreviewed publications and books authored by established authors.

Little validity should be given to data that derive from research that has been published without independent review or that has not been published. Data presented at scientific meetings also do not meet acceptable validity thresholds, even if scientific committees screening proposals for presentations of the studies involving the data had accepted the works. Another example involves reexamining data that had already been published in an effort to find support for secondary or ad hoc hypotheses. Similarly, journals should be wary of submissions that include data in increasingly larger samples as the original hypotheses are reinvestigated. To the detriment of good science, the chances increase for finding spurious results in situations such as these.

Another issue related to data in the field that has not been published or undergone peer review concerns meta-analyses of the empirical literature in the field. Meta-analyses are excellent means of evaluating the significance of data collected over multiple studies that address a particular issue. However, the technique is only as good as the data reported in the literature, and the quality of the latter should not be diluted by data with little validity nor should the meta-analyses include such data to begin with. These examples should not be considered inclusive, and authors must establish that their data will meet the double scrutiny in the field, from both scholarly reviewers and gate-keeping judges. It is only through procedures such as this, where data in the field meet the most rigorous of standards in terms of their reliability and validity, that the field, its researchers, and its practitioners can garner the respect needed in the psychological and legal arenas. For example, the field should not become one marked by either plaintiff- or defense-compatible research. In this regard, the publication policy of the journal PIL is guided by the principle that impartial science is critical to the field, and psychologists should govern their practice and testimony presented to court by the strictest of ethical standards (American Psychological Association 2002). The science in our discipline should speak in court rather than any opinion that is not fully based on it. 


\section{Submission Review Form}

Journal board member Ronald Ruff has suggested that reviewers consider using the following form (revised) in evaluating the quality of submitted manuscripts. It is shorter than the one described in Young (2008), and it allows for a rating score to be assigned to each relevant category. Reviewers might want to use this form as central to or as part of their evaluation.

\begin{tabular}{lllllllll}
\hline Evaluation & \multicolumn{1}{l}{ Negative } & \multicolumn{7}{c}{ Positive } \\
\hline Appropriate & 0 & 1 & 2 & 3 & 4 & 5 & 6 & 7 \\
Significance & 0 & 1 & 2 & 3 & 4 & 5 & 6 & 7 \\
Rigor of methodology-design & 0 & 1 & 2 & 3 & 4 & 5 & 6 & 7 \\
Clarity of the problem & 0 & 1 & 2 & 3 & 4 & 5 & 6 & 7 \\
Relevance/adequacy of & 0 & 1 & 2 & 3 & 4 & 5 & 6 & 7 \\
$\quad$ literature review & & & & & & & & \\
Adequacy of the data & 0 & 1 & 2 & 3 & 4 & 5 & 6 & 7 \\
Data analysis & 0 & 1 & 2 & 3 & 4 & 5 & 6 & 7 \\
Data interpretation & 0 & 1 & 2 & 3 & 4 & 5 & 6 & 7 \\
Contribution of new knowledge & 0 & 1 & 2 & 3 & 4 & 5 & 6 & 7 \\
Utility of tables/figures & 0 & 1 & 2 & 3 & 4 & 5 & 6 & 7 \\
Considers implications for practice & 0 & 1 & 2 & 3 & 4 & 5 & 6 & 7 \\
& & & & & & & &
\end{tabular}

In future issues of Psychological Injury and Law, I will periodically address other editorial policies. Suggestions for topics are welcome. My contact information is provided at the end of this editorial.

\section{References}

American Psychological Association (2002). Ethical principles of psychologists and code of conduct. Washington DC: Author.

American Psychological Association. (2009). Full disclosure of interests. Washington DC: Author. [www.apa.org/journals/ authors/disclosure_of interests.pdf] Downloaded January 18, 2009.

Bigler, E. D., Green, R. R., Farrer, T. J., Roper, J. C., \& Millward, J. B. (2009). The rigor of research design and 'forensic' publications in neuropsychological research. Psychological Injury and Law, 2.

Jacobs, J. A. (2007). Association law handbook: A practical guide for associations, societies, and charities (4th ed.). Washington, DC: ASAE and the Center for Association Leadership.

Jacobs, J. A., \& Ogden, D. W. (1995). Legal risk management for associations: A legal compliance guide for volunteers and employees of trade and professional associations. Washington, DC: American Psychological Association.

Williams, C. L, Butcher, J. N., Gass, C. S., Cumella, E., Kally, Z. (2009). Inaccuracies about the MMPI-2 Fake Bad Scale in the Reply by Ben-Porath, Greve, Bianchini, \& Kaufman (2009). Psychological Injury and Law, 2, in review.

Young, G. (2008). Psychological injury and law: Editorial introducing a journal and an association. Psychological Injury and Law, 1, 16.

Young, G. (2009). Association for Scientific Advancement in Psychological Injury and Law (ASAPIL): Administrative manual. Toronto: ASAPIL (online at www.asapilorg; January 18, version). 